\title{
Proteolysis by Neutrophils
}

\author{
RELATIVE IMPORTANCE OF CELL-SUBSTRATE CONTACT AND \\ OXIDATIVE INACTIVATION OF PROTEINASE INHIBITORS IN VITRO
}

\author{
Edward J. Campbell, Robert M. Senior, John A. McDonald, and \\ David L. Cox with technical assistance from Jeanne M. Greco and JiLl A. \\ LANDIS, Pulmonary Disease and Respiratory Care Division, Department of \\ Medicine, Washington University at The Jewish Hospital of St. Louis, \\ St. Louis, Missouri 63110
}

\begin{abstract}
A BSTRACT Polymorphonuclear leukocytes have been implicated in connective tissue injury in a variety of disease processes. To gain insight into mechanisms by which neutrophils might degrade connective tissue macromolecules in the presence of proteinase inhibitors, we have used a model system that allows neutrophils to be held in vitro under physiologic conditions in close proximity to a very proteinase-sensitive substrate, ${ }^{125}$ I-labeled fibronectin. We have found: $(a)$ neutrophils spread rapidly on the fibronectin substrate; (b) fibronectin proteolysis by neutrophils is largely attributable to released elastase, and is linearly related to cell number over the range of 2,000 to 30,000 cells per assay; $(c)$ oxidants released from neutrophils stimulated by opsonized zymosan or phorbol myristate acetate do not protect released elastase from inhibition by $\alpha_{1}$-proteinase inhibitor or $\alpha_{2}$-macroglobulin; $(d)$ neutrophil myeloperoxidase and enzymatically generated superoxide anion render $\alpha_{1}$-proteinase inhibitor ineffective against fibronectin proteolysis when neutrophils are added $30 \mathrm{~min}$ later; and $(e) \alpha_{1}$-proteinase inhibitor and $\alpha_{2}$-macroglobulin incompletely inhibit fibronectin proteolysis by neutrophils $(79.8 \pm 6.3$ and $73.5 \pm 12.0 \%$, respectively.) The data suggested that proteolysis due to neutrophils that are in contact with susceptible macromolecules may occur due to partial exclusion of inhibitors from the cell-substrate interface. Although confirming that $\alpha_{1}$-proteinase inhibitor is ineffective against neutrophil-derived proteolysis
\end{abstract}

This work was presented in part at the Annual Meeting of the American Federation for Clinical Research, 27 April 1981, and published in abstract form. 1981. Clin. Res. 29: 443a.

Address correspondence to Dr. Campbell, Pulmonary Division, Department of Medicine, The Jewish Hospital of St. Louis, 216 S. Kingshighway, St. Louis, MO 63110.

Received for publication 27 January 1982 and in revised form 2 July 1982. after exposure to oxidants, these studies did not support the hypothesis that oxidants released from stimulated neutrophils enhance activity of proteinases they release in the presence of $\alpha_{1}$-proteinase inhibitor. We anticipate that further studies with this test system will be helpful in defining conditions that modulate inflammatory connective tissue injury in diseases such as pulmonary emphysema and rheumatoid arthritis.

\section{INTRODUCTION}

Proteinases released into the extracellular space by stimulated neutrophils $(\mathrm{PMN})^{1}$ have the potential to produce tissue injury. PMN elastase (human leukocyte elastase; HLE) has attracted particular attention in this regard because of its putative role in the pathogenesis of pulmonary emphysema ( $I, 2)$, and also because of the wide range of other connective tissue proteins HLE degrades (3-7).

The extracellular space contains very high concentrations of proteinase inhibitors, which normally prevent connective tissue damage by released $P M N$ proteinases. Thus, for proteolytic tissue injury to be produced by HLE, either the released HLE must be present in quantities that exceed the proteinase-inhibitory capacity of the local tissue environment (as might occur when the PMN are in contact with the tissue substrate), or the effectiveness of proteinase inhibitors must be impaired.

\footnotetext{
${ }^{1}$ Abbreviations used in this paper: $\alpha_{1} \mathrm{PI}, \alpha_{1}$-proteinase inhibitor; $\alpha_{2} \mathbf{M}$, alpha ${ }_{2}$-macroglobulin; AAPVCK, methoxysuccinyl-alanine-alanine-proline-valine chloromethyl ketone; BSA, bovine serum albumin; DMSO, dimethyl sulfoxide; EIC, elastase-inhibitory capacity; FN, human plasma fibronectin; HLE, human leukocyte elastase; PBS, phosphatebuffered saline; PMA, phorbal myristate acetate; PMN, human peripheral blood neutrophils; PMSF, phenylmethylsulfonylfluoride; SOD, superoxide dismutase; TLCK, N, $\alpha-p$ tosyl-L-lysine chloromethyl ketone.
} 
Recent evidence from several laboratories indicates that the elastase inhibitory capacity (EIC) of $\alpha_{1}$-proteinase inhibitor $\left(\alpha_{1} \mathrm{PI}\right)$ is lost when this inhibitor is exposed to oxidants (8-14). Because stimulated PMN are a source of oxidant activity, it has been proposed that PMN may decrease the local EIC of $\alpha_{1}$ PI. Recent work indicates that oxidative inactivation of $\alpha_{1}$ PI by stimulated PMN may occur in vitro (15-17). These data suggested that PMN may create a local environment in which HLE is present in relative excess to nonoxidized $\alpha_{1}$ PI. Under such conditions, the released HLE would be able to produce connective tissue injury.

We have developed a model system similar to that described by Varani et al. (18) to clarify the potential of $\mathrm{PMN}$ to produce connective tissue injury in the presence of proteinase inhibitors. Stimulated PMN are held in short-term culture in close proximity to radiolabeled human plasma fibronectin (FN), an extremely proteinase-sensitive substrate (19). Proteolytic activity is readily quantified, and proteinase inhibitors can be included in the test system.

In this report, we demonstrate that oxidants released from stimulated neutrophils do not protect their released proteinases from inhibition by $\alpha_{1}$-PI or $\alpha_{2}$-macroglobulin $\left(\alpha_{2} \mathrm{M}\right)$. However, close contact between neutrophils and substrate results in proteolysis even in the presence of an excess of proteinase inhibitors. These results suggest that propinquity of stimulated PMN to susceptible macromolecules may result in proteolysis in vivo.

\section{METHODS}

Reagents. Phorbol myristate acetate (PMA), zymosan, dimethyl sulfoxide (DMSO), bovine serum albumin (BSA, Cohn fraction V, A-4503), and phenylmethylsulfonylfluoride (PMSF) were purchased from Sigma Chemical Co., St. Louis, MO. All other chemicals were reagent grade.

Enzymes and enzyme inhibitors. HLE was purified from human sputum, utilizing Trasylol-Sepharose and ion-exchange chromatography $(20,21)$, then lyophilized and stored at $-20^{\circ} \mathrm{C}$. The concentration of HLE in solution was based upon the extinction coefficient for the absorbance at $280 \mathrm{~mm}$ of a $1 \%$ solution $\left(\mathrm{E}_{280}^{1 \%}\right)$ of $9.85(22)$.

Human neutrophil myeloperoxidase (MPO) was purified from PMN obtained by leukapheresis of a normal donor (23). $1 \mathrm{U}$ of peroxidase activity decomposed $1 \mu \mathrm{mol}$ of hydrogen peroxide per minute at $25^{\circ} \mathrm{C}(24)$.

Superoxide dismutase (SOD; bovine blood, S-8254), catalase (bovine liver, C-30), xanthine oxidase, hyaluronidaseType I, lactic acid dehydrogenase-Type XI, trypsin (type IX), and $\beta$-glucuronidase-Type II were obtained from Sigma Chemical Co., St. Louis, MO. Lysozyme and chymotrypsin were purchased from ICN Pharmaceuticals, Cleveland, $\mathrm{OH}$. Pepsin was a product of Boehringer-Mannheim, Indianapolis, IN.

Human $\alpha_{1} \mathrm{PI}$ and human $\alpha_{2} \mathrm{M}$ (74 percent active by active site titration) were obtained from J. A. Pierce, Washington University School of Medicine, St. Louis, MO, and J. Travis,
University of Georgia, Athens, GA, respectively. N, $\alpha$ - $p$-tosyl-L-lysine chloromethyl ketone (TLCK) was purchased from Sigma Chemical Co., St. Louis, MO. Methoxysuccinylalanine-alanine-proline-valine-chloromethyl ketone (AAPVCK) was a gift from J. C. Powers, Georgia Institute of Technology, Atlanta, GA.

Enzyme assays. Elastase-like amidase activity (25) was measured with methoxysuccinyl-alanine-alanine-proline-valine-p-nitroanilide (MSAPN), obtained from Dr. J. C. Powers, Georgia Institute of Technology, Atlanta, GA. The elastase activity of supernatant fluids from PMN was assessed by the rate of change in optical density at $410 \mathrm{~nm}$ (DU-8 spectrophotometer, Beckman Instruments, Fullerton, CA) at $37^{\circ} \mathrm{C}$ in phosphate-buffered saline (PBS: $50 \mathrm{mM}$ phosphate, $150 \mathrm{mM} \mathrm{NaCl}, \mathrm{pH} 7.4$ ), and compared to the activity of purified HLE.

Assays for lysozyme (26), superoxide anion (27), and LDH (28) were performed according to published techniques.

$P M N$. Human PMN were separated from heparinized blood by Ficoll-Hypaque centrifugation (29). Residual erythrocytes were lysed with a cold solution of $0.15 \mathrm{M}$ $\mathrm{NH}_{4} \mathrm{Cl}, 10 \mathrm{mM} \mathrm{KHCO}$, and $1 \mathrm{mM}$ sodium EDTA, pH 7.2. The PMN were washed with RPMI 1640 medium and held at $4^{\circ} \mathrm{C}$ until used in the assays. Differential counting of cells deposited on glass slides with a cytocentrifuge (Cytospin, Shandon Southern Instrument Co., Sewickley, PA) and stained with Wright's stain revealed $\geq 95 \%$ PMN. In studies requiring stimulated neutrophils, either PMA (final concentration, $10 \mathrm{ng} / \mathrm{ml}$ ) or zymosan opsonized with fresh human serum $(1 \mathrm{mg} / \mathrm{ml})$ was added to the assay mixture at the appropriate time.

Assay of proteolytic activity using ${ }^{125}$ I-labeled FN. Plasma FN was purified from outdated human plasma (The Blood Bank of The Jewish Hospital of St. Louis, MO) as described (3), using lysine-Sepharose, gelatin-Sepharose, and DEAEcellulose chromatography. The $\mathrm{FN}$ was dialyzed against 0.05 $\mathrm{M}$ Tris- $\mathrm{HCl}, \mathrm{pH} 7.4$, adjusted to $1 \mathrm{mg} / \mathrm{ml}$ using a value of $\mathrm{E}_{280}^{1 \%}$ of $12.8(30)$, and stored at $-70^{\circ} \mathrm{C}$ in small aliquots.

FN was labeled with ${ }^{125}$ I using Enzymobeads as described in Bio-Rad Product Information 1060 (Bio-Rad Laboratories, Richmond, CA). The radiolabeling reaction mixture, contained in a $6 \times 50-\mathrm{mm}$ glass tube, included $\sim 1 \mathrm{mCi}$ carrierfree ${ }^{125} \mathrm{I}-\mathrm{NaI}$ (New England Nuclear, Boston, MA) in $10 \mu \mathrm{l}$, $25 \mu \mathrm{l}$ of $\mathrm{FN}$ solution (at least $1 \mathrm{mg} / \mathrm{ml}$ ), $25 \mu \mathrm{l}$ of $1.0 \mathrm{M}$ sodium phosphate buffer (pH 7.2), $25 \mu \mathrm{l}$ of fresh $1 \% \beta$-D-glucose and of $25 \mu$ l of hydrated Enzymobead suspension. After $30 \mathrm{~min}$ at room temperature, the contents of the tube were removed and desalted using a Sephadex G-25 column, $1 \times 5 \mathrm{~cm}$, equilibrated with PBS containing $1 \mathrm{mg} / \mathrm{ml}$ bovine serum albumin. Greater than $90 \%$ of the ${ }^{125} \mathrm{I}$ in the radiolabeled FN was precipitable by $5 \%$ trichloracetic acid and by rabbit antibody raised to purified $F N$. In addition, $>90 \%$ of the ${ }^{125} I$ in radiolabeled FN binds to gelatin, as would be expected for intact FN.

To prepare microtiter plates for proteinase assays, ${ }^{125}$ I-FN was diluted with unlabeled FN to yield 1,000-2,000 cpm/ $\mu \mathrm{g}$. $6 \mathrm{ml}$, containing $6 \mathrm{mg} \mathrm{FN}$, was transferred to a polypropylene tube and diluted with $34 \mathrm{ml}$ of $0.06 \mathrm{M}$ sodium barbital buffer, pH 9.6. $200 \mu \mathrm{l}(30 \mu \mathrm{g} \mathrm{FN}, 50,000 \mathrm{cpm})$ were pipetted into each flat-bottomed well of 96-well Cooke microtiter plates (1-223-29, Dynatech Labs., Alexandria, VA). The microtiter plates were placed into an oven at $37^{\circ} \mathrm{C}$ for 24-36 h until the wells were dry. Nonadherent FN was removed by adding $200 \mu \mathrm{l}$ of PBS to each well and incubating the plates at $37^{\circ} \mathrm{C}$ for $3 \mathrm{~h}$. The fluid was aspirated with a transfer pipette, and the PBS wash was repeated. The plates were covered with Parafilm-M (American Can Co., Green- 
wich, CT) and stored at $4^{\circ} \mathrm{C}$ until used. The prepared plates were stable for at least $2 \mathrm{wk}$.

Each ${ }^{125}$ I-FN coated well was filled with a total volume of $200 \mu$ l of the solution or cell suspension to be assayed for proteinase activity. All enzyme standards were tested at appropriate $\mathrm{pH}$ and buffer conditions for maximal catalytic activity. Assays of HLE were performed in RPMI 1640 medium and incubated in $5 \% \mathrm{CO}_{2} /$ air. For assays of PMNderived proteinase activity, PMN were always added after all the other reagents were in the wells. Following addition of the assay mixture, the plate was incubated at $37^{\circ} \mathrm{C}$ for $3 \mathrm{~h}$. This incubation provided excellent assay sensitivity. After incubation, the contents of the well were centrifuged for $60 \mathrm{~s}$ (Microfuge B, Beckman Instruments, Inc., Fullerton, CA) to remove cellular elements if present, then a $100-\mu l$ aliquot was removed and the ${ }^{125} \mathrm{I}$ was counted (Beckman Gamma 7000, Beckman Instruments, Inc.). Results were expressed as the amount of FN solubilized per well, calculated from the specific activity of the ${ }^{125} \mathrm{I}-\mathrm{FN}$.

Inhibition of PMN proteolysis by $\alpha_{1} P I$ and $\alpha_{2} M$. PMN were added to coated microtiter wells that contained activating agent (either PMA or opsonized zymosan) and the appropriate inhibitor. After a 3 -h incubation, proteolytic activity was quantified as described above. In additional experiments, catalase, SOD, DMSO, and hydrogen peroxide were present in the assay mixtures at the time of addition of PMN.

Inactivation of $\alpha_{1} P I$ by exogenous MPO and superoxide anion. Oxidative inactivation of $\alpha_{1}$ PI would be expected to result in an increased expression of proteolytic activity of PMN (due to loss of EIC of the inhibitor). To confirm that oxidative inactivation of $\alpha_{1}$ PI by PMN occurred under conditions described by others, and to ensure that loss of EIC was detectable by our test system, we studied the effect of addition of purified MPO and an enzymatic superoxide-generating system (xanthine and xanthine oxidase).

MPO $(16 \mathrm{mU} / \mathrm{ml})$ plus $\mathrm{H}_{2} \mathrm{O}_{2}(10 \mu \mathrm{M})$, or xanthine $(50$ $\mu \mathrm{M})$ plus xanthine oxidase $(0.6 \mu \mathrm{M})$, as described previously $(16,17)$, were added to coated microtiter wells that contained $325 \mathrm{ng} \alpha_{1}$ PI and PMA (final concentration, $10 \mathrm{ng} / \mathrm{ml}$ ) in RPMI-1640 salts. After a 30 -min incubation at $37^{\circ} \mathrm{C}$ in $5 \% \mathrm{CO}_{2}$ in air, 30,000 PMN were added. Control wells received either no $\alpha_{1}$ PI or no oxidants. After a 3-h incubation in the $\mathrm{CO}_{2}$ incubator, the solubilized ${ }^{125} \mathrm{I}$ was determined.

\section{RESULTS}

Effect of nonproteolytic proteins and $p H$ on the release of ${ }^{125} I$-peptides from ${ }^{125} I-F N$. After a $3-\mathrm{h}$ incubation at $37^{\circ} \mathrm{C}$ with $\mathrm{PBS}$, followed by drying, $\sim 40 \%$ $(14 \mu \mathrm{g})$ of the ${ }^{125} \mathrm{I}-\mathrm{FN}$ remained adherent to the microtiter wells. It was firmly bound to the plastic, as ${ }^{125}$ I representing $<0.2 \mu \mathrm{g} F N$ was released after an additional $3 \mathrm{~h}$ of incubation with PBS. 3-h incubations in buffers $(0.4 \mathrm{M})$ ranging in $\mathrm{pH}$ from 4 to 10 resulted in negligible differences from PBS (data not shown). Lactic acid dehydrogenase $(50 \mu \mathrm{g}), \beta$-glucuronidase $(50 \mu \mathrm{g})$ and lysozyme $(50 \mu \mathrm{g})$ released no ${ }^{125} \mathrm{I}$. BSA $(50 \mu \mathrm{g})$ and hyaluronidase $(50 \mu \mathrm{g})$ released 0.10 and $0.62 \mu \mathrm{g} \mathrm{FN}$, respectively, in a $3-\mathrm{h}$ assay. Thus, in the absence of proteolytic activity, ${ }^{125}$ I-FN remained firmly bound to the plates under the usual conditions used in proteinase assays. Partially purified human skin collagenase, which solubilized $200 \mu \mathrm{g}$ of native skin collagen/h, solubilized only $0.70 \mu \mathrm{gN}$ in the $3 \mathrm{~h}$ assay. Trypsin, chymotrypsin, and pepsin solubilized $0.44,0.17$, and $0.09 \mu \mathrm{g} \mathrm{FN}$, respectively, per nanogram enzyme in $3 \mathrm{~h}$. FN solubilization by trypsin in a $3-\mathrm{h}$ assay was linearly related to the amount of enzyme added over the range of 0.5 to $40 \mathrm{ng}$, and the ${ }^{125} \mathrm{I}$ solubilized was linearly related to duration of contact with substrate in assays extended to $6 \mathrm{~h}$. In $10^{125} \mathrm{I}-\mathrm{FN}$ coated wells on two different plates prepared from the same batch of labeled FN, 4 ng trypsin released $3,842 \pm 223$ (SD) $\mathrm{cpm} /$ well with one plate and $3,863 \pm 343 \mathrm{cpm}$ with the other, thus demonstrating excellent reproducibility of the assay.

FN solubilization by HLE. Solubilization of FN by HLE was linearly related to the amount of enzyme added per well in the range of 2 to $30 \mathrm{ng}$ of added HLE (Fig. 1).

FN solubilization by PMN. To estimate the speed with which PMN establish contact with the ${ }^{125}$ I-FN substrate in our experimental system, we carefully introduced $8 \cdot 10^{4} \mathrm{PMN}$ in $10 \mu \mathrm{l}$ at the upper surface of wells containing $190 \mu \mathrm{l}$ of RPMI salts, then followed the time course of cell settling and spreading by inverted phase microscopy. $1 \mathrm{~min}$ after addition of the cells, a substantial number had reached the well bottom, but all cells were rounded and phase-refringent. At $3 \mathrm{~min}$, we estimated that $<5 \%$ of the cells remained in suspension, and active spreading of PMN on the bottom well surface was evident. By 5 min after cell addition, nearly all of the PMN at the bottom of the well had spread on the substrate. When the PMN were observed again $60 \mathrm{~min}$ after their introduction, the cell distribution and morphology was essentially unchanged.

Fig. 2 shows $F N$ solubilization as a function of the number of PMN added per well. The observed pro-

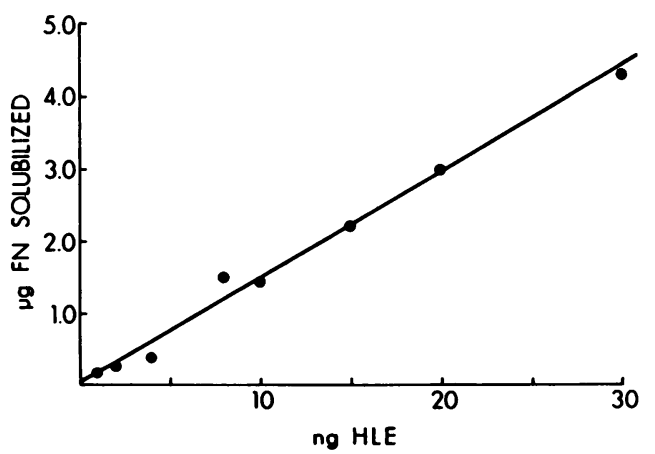

Figure 1 FN solubilization by HLE in a 3-h assay. Data points are the means of duplicate assays, and are shown along with the linear regression line determined by the data. Assays were performed in RPMI medium, at $37^{\circ} \mathrm{C}$, in an atmosphere of $5 \% \mathrm{CO}_{2}$ in air. 


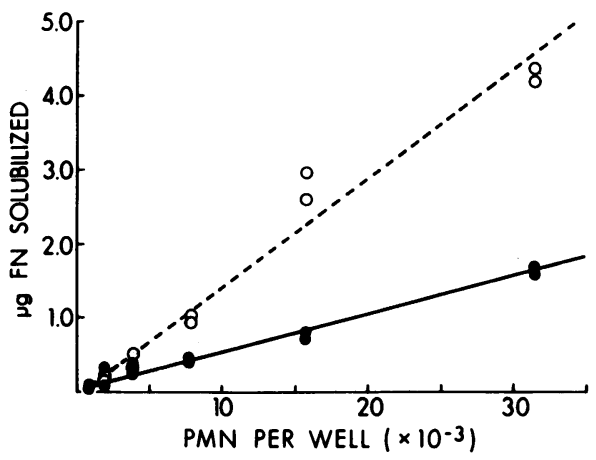

FIGURE 2 PMN-derived proteolytic activity. FN solubilization is shown as a function of the number of unstimulated PMN added per microtiter well (- - The effect of stimulation of the PMN with opsonized zymosan $(\mathrm{O}-\mathrm{O})$ is also shown. Each data point represents a single assay result. The lines are linear regression lines determined by the data. Assays were performed as described for Fig. 1 .

teolytic activity was linearly related to the number of cells per well over the range of 2,000 to 30,000 cells. Addition of a few thousand cells per well resulted in readily detectable proteolysis. Stimulation of the PMN with opsonized zymosan (Fig. 2) resulted in a 2.7 -fold increase in proteolytic activity. In subsequent studies of PMN-derived proteolytic activity, we used 30,000 cells per well.

Characterization of PMN-derived proteolytic activity. Several lines of evidence indicated that nearly all of the PMN-derived proteolytic activity against FN resulted from released HLE, as previous work has suggested $(31,32)(a)$ PMSF, $1 \mathrm{mM}$, inhibited nearly all of the proteolytic activity of $25 \mathrm{ng}$ of HLE (an amount of enzyme producing proteolytic activity comparable to 30,000 PMN). PMSF also nearly completely inhibited the proteolytic activity derived from PMN (Table I). Although slightly less inhibition of proteolytic activity by PMSF was observed for PMN than for HLEderived proteolytic activity, the differences did not reach statistical significance $(P=0.10, t$ test $)$. (b) The elastase-specific inhibitor AAPVCK, $300 \mu \mathrm{M}$, inhibited PMN-derived proteolytic activity as completely as did PMSF (Table I). The inhibitory effect was not due to toxicity of the AAPVCK toward PMN (preventing release of proteolytic activity), since the PMN phagocytized zymosan normally in the presence of AAOPVCK, with release of lysozyme and superoxide anion, but not LDH. TLCK (a chloromethyl ketone inhibitor of trypsin but not elastase) produced minimal inhibition of PMN-derived proteolytic activity. $(c)$ The elastase activity released from stimulated PMN, as measured with MSAPN, completely accounted for the observed FN proteolysis.

Since released HLE was responsible for PMN-de- rived proteolysis of $\mathrm{FN}$ in the assay, the effects of proteinase inhibitors upon purified HLE and PMN-derived proteolytic activity were compared in the following experiments.

Inhibition of PMN-derived proteolytic activity by $\alpha_{1} P I$. Preliminary experiments revealed that $325 \mathrm{ng}$ $\alpha_{1}$ PI was just sufficient to completely inhibit $25 \mathrm{ng}$ of purified HLE (the quantity released by 30,000 PMN, Fig. 3). Therefore, to provide maximum sensitivity for detecting inhibitor inactivation, $325 \mathrm{ng} \alpha_{1}$ PI was tested for its ability to inhibit the proteolytic activity of 30,000 PMN.

Alpha $_{1}$ PI inhibited $79.8 \pm 6.3(\mathrm{SD}) \%$ of the PMN-derived proteolytic activity (Fig. 3).

Addition of catalase, SOD, or DMSO to the assays, to catalytically degrade or scavenge hydrogen peroxide, superoxide anion, or hydroxyl radical, respectively, did not significantly increase the inhibitory capacity of the $\alpha_{1}$ PI toward PMN-derived proteolytic activity (Fig. 3). Although stimulated PMN should themselves be a source of sufficient hydrogen peroxide, as a result of spontaneous or enzymatic dismutation of superoxide anion (27), to serve as a substrate for catalytic activity of MPO, we tested the effect of exogenous hydrogen peroxide on the test system. No increase in proteolysis was observed (Fig. 3).

When the inhibition by $\alpha_{1}$ PI of PMN-derived proteolytic activity was compared with its inhibition of HLE having comparable enzymatic activity, the inhibition of PMN-derived proteolytic activity was less $(P<0.001, t$ test; Fig. 3). This observation demonstrated that $\alpha_{1}$ PI inhibited elastase derived from viable PMN (when the cells were in contact with the substrate) less well than it inhibited purified HLE.

Although the amount of $\alpha_{1} \mathrm{PI}$ used in the experiments shown in Fig. 3 was carefully chosen (see above), three additional concentrations were tested in each experiment. The results were qualitatively unchanged regardless of inhibitor concentration used: PMN-de-

TABLE I

Inhibition of PMN-derived Proteolytic Activity

\begin{tabular}{|c|c|c|c|c|}
\hline \multirow[b]{2}{*}{ Inhibitor ${ }^{\bullet}$} & \multicolumn{2}{|c|}{ HLE (25 ng) } & \multicolumn{2}{|c|}{$\operatorname{PMN}\left(30 \cdot 10^{8}\right)$} \\
\hline & $n \ddagger$ & Inhibition & $n$ & Inhibition \\
\hline & & $\% \pm S D$ & & $\% \pm S D$ \\
\hline PMSF, $1 \mathrm{mM}$ & 4 & $95( \pm 6)$ & 6 & $89( \pm 3)$ \\
\hline AAPVCK, $60 \mu \mathrm{M}$ & 4 & $98( \pm 4)$ & 6 & $92( \pm 9)$ \\
\hline
\end{tabular}

- HLE or PMN added to an assay solution containing inhibitor plus opsonized zymosan $(1 \mathrm{mg} / \mathrm{ml}$ final concentration in RPMI 1640 medium). Assays performed as described for Fig. 1.

$\ddagger$ Number of assays performed. 


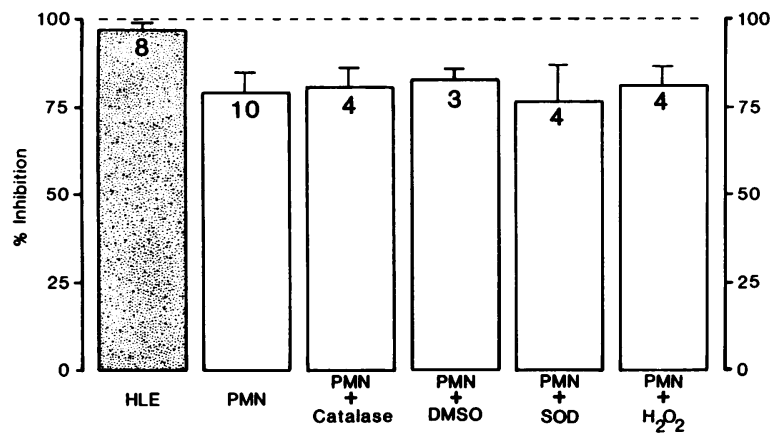

FIgURE 3 Inhibition of PMN-derived proteolytic activity by $\alpha_{1} \mathrm{PI}$. The PMN $(30,000$ cells/well) were stimulated with opsonized zymosan or PMA. For comparison, inhibition of $25 \mathrm{ng}$ of purified HLE is shown (see text). All reagents were present in the assay mixture at the time of addition of PMN. The lines above the bars represent standard deviations, while the number of assays performed appears near the top of each bar. The amounts of the various reagents used are as follows: $\alpha_{1} \mathrm{PI}, 325 \mathrm{ng}$; catalase, $1,000 \mathrm{U} / \mathrm{ml}$; DMSO, $1 \%$ (vol/vol); SOD, $50 \mu \mathrm{g} / \mathrm{ml} ; \mathrm{H}_{2} \mathrm{O}_{2}, 10 \mu \mathrm{M}$. The PMN were stimulated with either PMA, $10 \mathrm{ng} / \mathrm{ml}$ (two assays in each PMN group) or opsonized zymosan $(1 \mathrm{mg} / \mathrm{ml})$. The choice of PMN-stimulating agent did not affect the results.

rived proteolysis was substantially, but incompletely, inhibited. The results $(n=10$, each group), expressed as percent inhibition of PMN-derived proteolysis $\pm \mathrm{SD}$ for each amount of $\alpha_{1} \mathrm{PI}$, are as follows: $7.5 \mu \mathrm{g}$, $84.1 \pm 9.5 \% ; 1.88 \mu \mathrm{g}, 79.8 \pm 6.4 \%$; $469 \mathrm{ng}, 70.9 \pm 11.1 \%$; and $64 \mathrm{ng}, 45.9 \pm 21.8 \%$.

Inactivation of $\alpha_{1}$ PI by exogenous MPO and superoxide anion. In the presence of $325 \mathrm{ng} \alpha_{1} \mathrm{PI}$, 30,000 PMN solubilized $1.40 \pm 0.14$ (SD) $\mu$ g FN in 3 h. In marked contrast, when the $\alpha_{1}$ PI was exposed to $16 \mathrm{mU} / \mathrm{ml}$ MPO or exogenous superoxide anion (50 $\mu \mathrm{M}$ xanthine plus $0.6 \mu \mathrm{M}$ xanthine oxidase) for $30 \mathrm{~min}$ before addition of PMN, the FN solubilization observed was $3.75 \pm 1.33$ and $3.93 \pm 0.13 \mu \mathrm{g}$, respectively $(P<0.01$ for both comparisons, $t$ test $)$. The FN solubilization when the $\alpha_{1}$ PI was incubated with oxidants was not significantly different from that observed in the absence of $\alpha_{1}$ PI (Fig. 2), indicating complete loss of the EIC of $\alpha_{1}$ PI under these conditions, as reported by others $(16,17)$.

Thus, the lack of inactivation of $\alpha_{1}$ PI by stimulated PMN alone was not due to inability of the FN plate test system to detect loss of EIC by oxidant-exposed $\alpha_{1}$ PI.

Inhibition of PMN-derived proteolytic activity by $\alpha_{2} M$. Preliminary experiments revealed that $3.54 \mu \mathrm{g}$ of $\alpha_{2} \mathrm{M}$ was just sufficient to completely inhibit the activity of $25 \mathrm{ng}$ of HLE (Fig. 4). Accordingly, this amount of $\alpha_{2} \mathrm{M}$ was used in experiments examining inhibition of PMN-derived proteolytic activity, for reasons outlined above; $73.5 \pm 12.0 \%$ of the proteolytic activity was inhibited (Fig. 4). As with $\alpha_{1}$ PI, the presence of catalase, SOD, and exogenously added hydrogen peroxide failed to alter the observed inhibition.

Less inhibition of PMN-derived proteolytic activity than of HLE was observed $(P<0.001, t$ test; Fig. 4).

Two additional concentrations of $\alpha_{2} \mathrm{M}$ were also tested in each experiment. The results $(n=10$, each group), expressed as percent inhibition of PMN-derived proteolysis \pm SD for each amount of $\alpha_{2} \mathrm{M}$, are as follows: $14.2 \mu \mathrm{g}, 80.8 \pm 12.1 \%$; $3.54 \mu \mathrm{g}, 73.4 \pm 12.0 \%$; and $884 \mathrm{ng}, 51.1 \pm 17.3 \%$. These findings are similar to those for $\alpha_{1} \mathrm{PI}$.

\section{DISCUSSION}

The model system described in this report has permitted the rapid, accurate quantification of proteolysis by a few thousand PMN when placed in contact with a substrate that is extremely sensitive to proteolytic degradation. Although the substrate used ( ${ }^{125}$ I-labeled FN) is sensitive to a variety of proteinases as previously reported and confirmed here, it was evident that nearly all of the FN proteolytic activity from stimulated PMN resulted from released HLE. Our test system mimics the in vivo situation to the extent that $(a)$ stimulated PMN were examined at physiologic temperature, $\mathrm{pH}$, and salt concentrations; (b) the inhibitors and cells tested were all of human origin; and $(c)$ the PMN were in close proximity to a connective tissue substrate.

The model system reported here has enabled in vitro study of the hypothesis that PMN-derived oxidants increase the local vulnerability of tissues to proteinases released by PMN by oxidatively inactivating proteinase inhibitors in the cellular microenvironment. Pre-

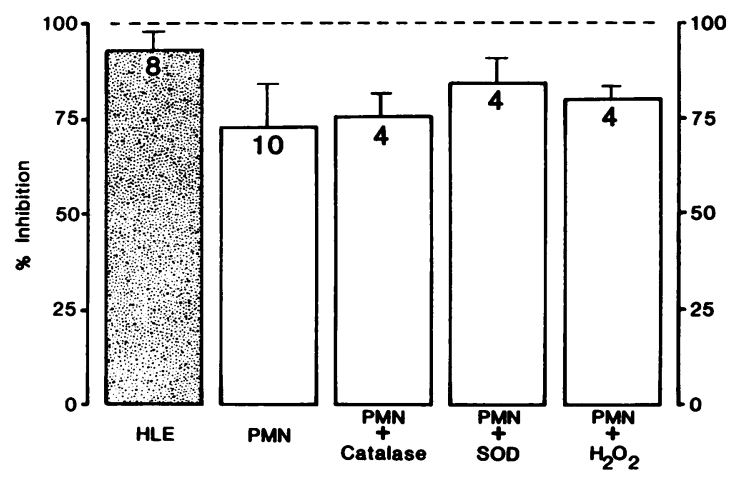

FIGURE 4 Inhibition of proteolytic activity of 30,000 PMN by $3.54 \mu \mathrm{g} \alpha_{2} \mathrm{M}$ (see text). Inhibition of $25 \mathrm{ng}$ of purified HLE is shown for comparison. The PMN were stimulated with PMA, $10 \mathrm{ng} / \mathrm{ml}$ (two assays in each PMN group) or opsonized zymosan $(1 \mathrm{mg} / \mathrm{ml})$. See Fig. 3 for remainder of assay conditions. 
vious lines of in vitro evidence supporting this hypothesis included (a) $\alpha_{1}$ PI contains a critical methionine residue at its active site that is oxidized to methionine sulfoxide by the action of various oxidants, with resultant loss of its inhibitory activity against elastase $(10,12,13)$; (b) stimulated PMN release a variety of oxidants capable of diminishing the EIC of $\alpha_{1} \mathrm{PI}$, including components of the myeloperoxidasehydrogen peroxide-halide system (14), superoxide anion (33), and hydroxyl radical (34); and (c) stimulated PMN, when incubated with $\alpha_{1} \mathrm{PI}$, reduce its EIC (15-17).

Earlier in vitro experiments that examined the possibility that PMN-derived oxidants inactivate $\alpha_{1} \mathrm{PI}$ quantified the loss of EIC of $\alpha_{1}$ PI in PMN supernatant fluids by gel filtration or elastase assay, using porcine pancreatic elastase, not HLE. In contrast to pancreatic elastase, HLE binds to oxidized $\alpha_{1}$ PI with lowered affinity. Matheson et al. allude to difficulties in studying the interaction of oxidized $\alpha_{1}$ PI with HLE because the enzyme could either form a complex with the oxidized $\alpha_{1}$ PI or convert it to a modified form (14). The activity of released PMN proteinases was not examined in the previous studies of inactivation of $\alpha_{1}$ PI by PMN.

Stimulated PMN do appear to oxidatively inactivate $\alpha_{1} \mathrm{PI}$ under some conditions (15-17). The most convincing lines of evidence in this regard have been the reduction in $\alpha_{1}$ PI inactivation in the presence of antagonists of neutrophil oxidants, the lack of inactivation of $\alpha_{1}$ PI by oxidant-deficient neutrophils (derived from patients with chronic granulomatous disease or hereditary MPO deficiency), and the partial restoration of lost EIC by reducing agents. Neutrophil-derived oxidants were thought to be responsible for oxidized $\alpha_{1}$ PI found in rheumatoid synovial fluid (35).

Since our test system readily detected loss of EIC by $\alpha_{1}$ PI when it was exposed to exogenously added myeloperoxidase and superoxide anion, we were initially surprised to find that $\alpha_{1} \mathrm{PI}$ in limited quantities substantially inhibited elastase activity from stimulated PMN (PMA or opsonized zymosan), and that the observed inhibition was not altered by addition of reagents that reduce (SOD, catalase, and DMSO) or enhance (hydrogen peroxide) the activity of PMN-derived oxidants. Similar results were obtained with the other major circulating elastase inhibitor, $\alpha_{2} M$, confirming that $\alpha_{2} \mathrm{M}$ was not susceptible to oxidative inactivation under the conditions tested (17).

Under the conditions tested, we have found no evidence that PMN-derived oxidants potentiated FN proteolysis in the presence of proteinase inhibitors. It is important to note that our work does not conflict with data indicating that cigarette smoke oxidants are capable of inactivating proteinase inhibitors $(8,9,36$, 37 ). It also does not indicate that PMN-derived oxi- dants are unable to inactivate $\alpha_{1}$ PI (exogenously supplied MPO and superoxide anion did inactivate $\alpha_{1} \mathrm{PI}$ in our system).

While searching for the explanation for the lack of oxidant-mediated enhancement of PMN-derived elastase activity in the presence of $\alpha_{1} \mathrm{PI}$, we developed an appreciation for the complex dynamics of PMN degranulation in a microenvironment in which the cells are closely applied to a proteinase-sensitive substrate, but bathed in proteinase inhibitors. Many variables that would not influence the results of previous experiments became critically important in our test system. These include $(a)$ the timing of release of oxidants in relation to the release of proteinases from the PMN, since oxidants prevent binding of $\alpha_{1}$ PI to proteinases but do not dissociate proteinase- $\alpha_{1}$ PI complexes once formed (unpublished observations); (b) the concentration of PMN (since inhibition of PMN-derived elastase is stoichiometric, while inactivation of $\alpha_{1} \mathrm{PI}$ may be both stoichiometric, in the case of reactive oxygen species, or catalytic, in the case of MPO); and (c) the area of contact between the PMN and the substrate, from which proteinase inhibitors may be partially excluded. The possibility that inhibitor oxidation by stimulated PMN might be prevented by interfering substances such as free methionine (17) in the RPMI medium was excluded by the lack of $\alpha_{1}$ PI inactivation by stimulated $P M N$ when the assay was performed in a medium containing only RPMI salts, glucose, and bicarbonate (unpublished observations). It is noteworthy that oxidation of $\alpha_{1}$ PI by MPO is optimized by acid pH (6.2) and low ionic strength (14), as opposed to the relatively physiologic conditions used in our studies. It is also interesting to speculate that PMN contain an enzymatic activity capable of reducing protein-bound methionine sulfoxide, as has been described for other mammalian tissues (38), which might restore the EIC of oxidized $\alpha_{1}$ PI.

Regardless of the explanation for the lack of significant oxidative inactivation of proteinase inhibitors under the conditions we tested, it is noteworthy that $\alpha_{1} \mathrm{PI}$ and $\alpha_{2} \mathrm{M}$ did not inhibit elastase released from PMN as effectively as they inhibited purified PMN elastase in solution. A likely explanation for this phenomenon is that the inhibitors are partially excluded from the interface between the PMN and the substrate, allowing relatively unrestrained proteolysis to occur in that microenvironment. Our observation of rapid spreading of PMN on the FN substrate supports this explanation. This conclusion was also reached in a recent study (39) that used rat PMN in contact with hemoglobin bound to plastic. Proteolysis by the rat PMN stimulated by surface-bound immune complexes was relatively poorly inhibited by fluid-phase inhibitors. The fact that proteolysis by rat PMN was largely 
attributable to a trypsin-like neutral proteinase (39) rather than an elastase resembling HLE, however, emphasizes the need for use of human PMN in this system if the results are to be extrapolated to human disease.

In summary, in a test system in which stimulated PMN can be held in close proximity to a proteinasesensitive connective tissue substrate, no evidence was found for oxidative inactivation of proteinase inhibitors despite the observation that the test system readily detected loss of the EIC of $\alpha_{1}$ PI by exogenously added oxidants. The data suggested that under the conditions tested, partial exclusion of proteinase inhibitors from the PMN-connective tissue substrate interface might be an important mechanism by which PMN-mediated proteolysis can occur in the presence of an excess of proteinase inhibitors. The data also suggest that therapeutic strategies in human diseases characterized by ongoing connective tissue injury may not be adequate if they are directed toward enhancing local proteinase inhibitory activity in an attempt to prevent connective tissue from proteolysis during inflammation.

We anticipate that the FN microtiter plate system will provide a fruitful means for further delineating conditions that modulate connective tissue proteolysis in diseases such as pulmonary emphysema and rheumatoid arthritis.

\section{ACKNOWLEDGMENTS}

This work was supported in part by U. S. Public Health Service grants HL 24265, HL 16118, and HL 26009.

\section{REFERENCES}

1. Senior, R. M., H. Tegner, C. Kuhn, K. Ohlsson, B. Starcher, and J. A. Pierce. 1977. The induction of pulmonary emphysema with human leukocyte elastase. Am. Rev. Respir. Dis. 116: 469-475.

2. Janoff, A., B. Sloan, G. Weinbaum, V. Damiano, R. A. Sandhaus, J. Elias, and P. Kimbel. 1977. Experimental emphysema induced with purified human neutrophil elastase: tissue localization of the instilled protease. Am. Rev. Respir. Dis. 115: 461-478.

3. McDonald, J. A., and D. G. Kelley. 1980. Degradation of fibronectin by human leukocyte elastase. Release of biologically-active fragments. J. Biol. Chem. 255: 88488858.

4. Gadek, J. E., G. A. Fells, D. G. Wright, and R. G. Crystal. 1980. Human neutrophil elastase functions as a type III collagen "collagenase". Biochem. Biophys. Res. Commun. 95: 1815-1822.

5. Mainardi, C. L., S. N. Dixit, and A. H. Kang. 1980. Degradation of type IV (basement membrane) collagen by a proteinase isolated from human polymorphonuclear leukocyte granules. J. Biol. Chem. 255: 5435-5441.

6. Roughley, P. J. 1977. The degradation of proteoglycan by leukocyte elastase. Biochem. Soc. Trans. 5: 443-445.

7. Janoff, A. 1975. At least three human neutrophil lysosomal proteases are capable of degrading joint connective tissues. Ann. N. Y. Acad. Sci. 256: 402-407.

8. Janoff, A., and H. Carp. 1977. Possible mechanisms of emphysema in smokers: cigarette smoke condensate suppresses protease inhibition in vitro. Am. Rev. Respir. Dis. 116: 65-72.

9. Carp, H., and A. Janoff. 1978. Possible mechanism of emphysema in smokers: In vitro suppression of serum elastase-inhibitory capacity by fresh cigarette smoke and its prevention by antioxidants. Am. Rev. Respir. Dis. 118: 617-621.

10. Johnson, D. A., and J. Travis. 1978. Structural evidence for methionine at the reactive site of human $\alpha$-1-proteinase inhibitor. J. Biol. Chem. 253: 7142-7144.

11. Cohen, A. B. 1979. The effects in vivo and in vitro of oxidative damage to purified $\alpha_{1}$-antitrypsin and to the enzyme-inhibiting activity of plasma. Am. Rev. Respir. Dis. 119: 953-960.

12. Matheson, N. R., P. S. Wong, and J. Travis. 1979. Enzymatic inactivation of human alpha-1-proteinase inhibitor by neutrophil myeloperoxidase. Biochem. Biophys. Res. Commun. 88: 402-409.

13. Johnson, D. A. 1980. Ozone inactivation of human $\alpha_{1-}$ proteinase inhibitor. Am. Rev. Respir. Dis. 121: 10311038.

14. Matheson, N. R., P. S. Wong, M. Schuyler, and J. Travis. 1981. Interaction of human $\alpha$-1-proteinase inhibitor with neutrophil myeloperoxidase. Biochemistry. 20: 331-336.

15. Carp, H., and A. Janoff. 1979. In vitro suppression of serum elastase-inhibitory capacity by reactive oxygen species generated by phagocytosing polymorphonuclear leukocytes. J. Clin. Invest. 63: 793-797.

16. Carp, H., and A. Janoff. 1980. Potential mediator of inflammation: Phagocyte-derived oxidants suppress the

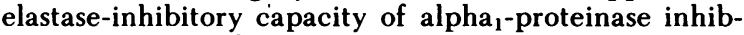
itor in vitro. J. Clin. Invest. 66: 987-995.

17. Clark, R. A., P. J. Stone, A. El Hag, J. D. Calore, and C. Franzblau. 1981. Myeloperoxidase-catalyzed inacti-

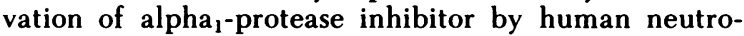
phils. J. Biol. Chem. 256: 3348-3353.

18. Varani, J., K. Johnson, and J. Kaplan. 1980. Development of a solid-phase assay for measurement of proteolytic enzyme activity. Anal. Biochem. 107: 377-384.

19. McDonald, J. A., B. J. Baum, D. M. Rosenberg, J. A. Kelman, S. C. Brin, and R. G. Crystal. 1979. Destruction of a major extracellular adhesive glycoprotein (fibronectin) of human fibroblasts by neutral proteases from polymorphonuclear leukocyte granules. Lab. Invest. 40: 350-357.

20. Martodam, R. R., R. J. Baugh, D. Y. Twamasi, and I. E. Liener. 1979. A rapid procedure for the large scale purification of elastase and cathepsin $\mathrm{G}$ from human sputum. Prep. Biochem. 9: 15-31.

21. Campbell, E. J., R. R. White, R. M. Senior, R. J. Rodriguez, and C. Kuhn. 1979. Receptor-mediated binding and internalization of leukocyte elastase by alveolar macrophages in vitro. J. Clin. Invest. 64: 824-833.

22. Babul, J., and E. Stellwagen. 1969. Measurement of protein concentration with interference optics. Anal. Biochem. 28: 216-221.

23. Matheson, N. R., P. S. Wong, and J. Travis. 1970. Isolation and properties of human neutrophil myeloperoxidase. Biochemistry. 20: 325-330.

24. Worthington Biochemical Company. 1972. Peroxidase. In Worthington Enzyme Manual. Worthington Biochemical Corp., Freehold, NJ. 43-45.

25. Castillo, M. J., K. Najakima, M. Zimmerman, and J. C. Powers. 1979. Sensitive substrates for human leukocyte and porcine pancreatic elastase: a study of the merits of 
various chromophoric and fluorogenic leaving groups in assays for serine proteases. Anal. Biochem. 99: 53-64.

26. Osserman, E. F., and D. P. Lawlor. 1966. Serum and urinary lysozyme (muramidase) in monocytic and monomyelocytic leukemia. J. Exp. Med. 124: 921-951.

27. McCord, J. M., and I. Fridovich. 1969. Superoxide dismutase. An enzymatic function for erythrocuprein (hemocuprein). J. Biol. Chem. 244: 6049-6055.

28. Lowry, O. H., and J. V. Passonneau. 1972. A Flexible System of Enzymatic Analysis. H. D. Brown, editor. Academic Press, Inc., New York.

29. Böyum, A. 1968. Isolation of mononuclear cells and granulocytes from human blood: isolation of mononuclear cells by one centrifugation, and of granulocytes by combining centrifugation and sedimentation at $\mathbf{l} \mathrm{g}$. Scand. J. Clin. Lab. Invest. 21(Suppl. 97): 77-89.

30. Mosesson, M. W., and R. A. Umfleet. 1970. The coldinsoluble globulin of human plasma. I. Purification, primary characterization, and relationship to fibrinogen and other cold-insoluble fraction components. J. Biol. Chem. 245: 5728-5736.

31. McDonald, J. A., D. G. Kelley, and E. J. Campbell. 1980. Characterization of the major human neutrophil elastase degradation products of fibronectin. Clin. Res. 28: 429A. (Abstr.).

32. Schmidt, W. 1978. Differential release of elastase and chymotrypsin from polymorphonuclear leukocytes. In Neutral Proteases of Human Polymorphonuclear Leu- kocytes. K. Havemann and A. Janoff, editors. Urban Schwarzenberg, Baltimore. 77-79.

33. Babior, B. M., R. S. Kipnes, and J. T. Curnutte. 1973. Biological defense mechanisms: the production by leukocytes of superoxide, a potential bactericidal agent. $J$. Clin. Invest. 52: 741-744.

34. Weiss, S. J., P. K. Rustagi, and A. F. LoBuglio. 1978. Human granulocyte generation of hydroxyl radical. $J$. Exp. Med. 147: 316-323.

35. Wong, P. S., and J. Travis. 1980. Isolation and properties of oxidized alpha-1-proteinase inhibitor from human rheumatoid synovial fluid. Biochem. Biophys. Res. Commun. 96: 1449-1454.

36. Janoff, A., H. Carp, D. K. Lee, and R. T. Drew. 1979. Cigarette smoke inhalation decreases $\alpha_{1}$-antitrypsin activity in rat lung. Science (Wash., DC). 206: 1313-1314.

37. Gadek, J. E., G. A. Fells, and R. G. Crystal. 1979. Cigarette smoking induces functional antiprotease deficiency in the lower respiratory tract of humans. Science (Wash., DC). 206: 1315-1316.

38. Brot, N., L. Weissbach, J. Werth, and H. Weissbach. 1981. Enzymatic reduction of protein-bound methionine sulfoxide. Proc. Natl. Acad. Sci. USA. 78: 2155-2158.

39. Johnson, K. J., and J. Varani. 1981. Substrate hydrolysis by immune complex-activated neutrophils: effect of physical presentation of complexes and protease inhibitors. J. Immunol. 127: 1875-1879. 